http://www.jfas.info

\title{
MODELLING EQUATION OF KNEE FORCE DURING INSTEP KICKING USING DOMINANT'S LEG IN FOOTBALL
}

\author{
M. F. M. Ali ${ }^{1}$, N. Yaakub ${ }^{2,}$, , M. N. Haris ${ }^{2}$ and M. K. A. Kamarudin ${ }^{3}$ \\ ${ }^{1}$ Faculty of Creative Technology and Heritage, Universiti Malaysia Kelantan, 16300 Bachok, \\ Kelantan, Malaysia \\ ${ }^{2}$ Faculty of Bioresources and Food Industry, Universiti Sultan Zainal Abidin, 22200 Besut, \\ Terengganu, Malaysia \\ ${ }^{3}$ East Coast Environmental Research Institute (ESERI), Universiti Sultan Zainal Abidin, Gong \\ Badak Campus, 21300 Terengganu, Malaysia
}

Published online: 08 August 2017

\begin{abstract}
This paper presents the biomechanics analysis of the football players, to obtain the equation that relates with the variables and to get the force model equation when the kicking was made. The subjects delivered instep kicking by using the dominant's leg where one subjects using right and left leg. 2 Dimensional analysis was conducted by using Silicon Pro Coach software. Based on the findings, the velocity and distance was identified as significant to the kick force model. The highest average force of kicking for dominant's right leg is $5879.60 \mathrm{~N}$, the highest average velocity is $8.2 \mathrm{~m} / \mathrm{s}$ with distance kick as much as $47.85 \mathrm{~m}$ and the multi linear model equation is $\hat{y}=-18.1+711 x_{1}+0.146 x_{2}+396 x_{3}$. The highest average force for dominant's left leg is $8486.0 \mathrm{~N}$, the highest average velocity is $11.71 \mathrm{~m} / \mathrm{s}$ with distance kick as much as $50.8 \mathrm{~m}$ and the multi linear model equation is $\hat{\mathrm{y}}=-0.073+724 \mathrm{x}_{1}+0.00114 \mathrm{x}_{2}+0.40 \mathrm{x}_{3}$.
\end{abstract}

Keywords: kicking; biomechanics; distance; force; velocity; angle.

Author Correspondence, e-mail: nadzifah@unisza.edu.my

doi: $\underline{\text { http://dx.doi.org/10.4314/jfas.v9i2s.46 }}$ 


\section{INTRODUCTION}

Football is the most popular team sports game around the world $[6,10]$. Football also remains the fastest growing team sport and in consequence of its popularity, attracting many young players all over the world. Though the top team players participate in national and international levels, the popularity of the game is reflected by millions who participate in football at all level of age. There are also no boundaries in terms of age limit or gender. They may play football routinely as recreational activity on streets and country side. This games applied a lot of skills such as control play, counter attack, running, dribbling, passing and kicking which are commonly used during the game. This game gives full enjoyment to those who are watching or playing it [2].

High quality kicking technique is the most typical specific technique of kinesiology in the football game. In order to understand the scientific work behind this skill, fundamental of kicking kinematics movement is particularly important for guiding and monitoring the training process [6-7]. Successful kicks need to be fast and accurate, especially when kicking on goal. The distance, velocity and angle imposed kicking are the important parameters involving the kicking activities where it can contribute high impact to effectiveness of kicking [5]. Instep kicking has been studied from the youngest age groups to seasoned professionals $[3,8]$. Based on all types of kicking, direct shot or instep kick was the highest velocity can be performed $[1,4]$. The full instep kicking give the highest result in kicking accuracy compared to inner instep and side foot kick [11]. The full instep kick also has been biomechanically studied in detail defining its typical components including the foot/ball contact phase.

Science and technology development has propelled all researchers develop worldwide variety field which among them is in field of sports. All researchers have made numerous studies about performance and development of athlete at every sort of game with used biomechanics method which it to increase sports development quality. The biomechanics of kicking in the soccer sport also is particularly important for guiding and monitoring the training process. Studies in the biomechanics of instep kicking have been focusing on numerous variables in different populations, all seek for the establishment of the optimal variables or variables that might be most predictive of success in instep kicking, with success being most typically 
defined by resultant to the ball velocity. This knowledge and understanding can assist to enhance the learning and performance of those skills [9].

Therefore, this study will be focusing on the biomechanics analysis with respect to the right and left leg of a football players besides to identify their kicking action and technique using the instep kick. In this research, the quantitative biomechanics analysis was performed. This study was executed by conducting quantitative measurement as well as quantitative biomechanics analysis. On the other hand, if the aspect is assessed by observation and survey, the results of the analysis are known as qualitative biomechanical analysis.

\section{METHODOLOGY}

\subsection{Subject Selection}

The subjects was selected is from professional football player with average heights of Asian. The subject were making instep kicking by using the dominant's leg (right and left). Most important thing is subject has to be in good health during experiment because the kicking that will be done is from self-force. In addition, selected subjects in this study were required to play at different positions such as: striker, midfield and defender. First screening process was held to select subjects with dominant's right and left leg. In this screening process, the subjects also had been test for injuries that carried out accordingly to the physiotherapy testing standard. The subjects need be free from any injury at lower limb part for at least six months before the experiments conducted. The demographic and anthropometric data were taken from the subjects.

\subsection{Experimental Setup}

The study was conducted on the field of National Sports Institute (ISN). Deflection marker was used on the lower limb of the subject for data recording of the analysis. Place to perform experiment also would be fixed by using cone which distance between cone would be fixed namely as much as a 1 meter. A FIFA approved soccer ball inflated at the regulation pressure was used in the test. The mass of the ball was $0.425 \mathrm{~kg}$. Position of ball is centered middle of cone. Two cameras will be using for this study that have been place at the front and side view. The camera will focus on the lower limb of the subject when the subjects deliver a kicking to 
get a better visualized. Data recording were done with video/picture using Sony video camera. This camera can analyze as fast as 0.02 seconds per frame. Fig. 1 shows the study setup for subject deliver an instep kicking.

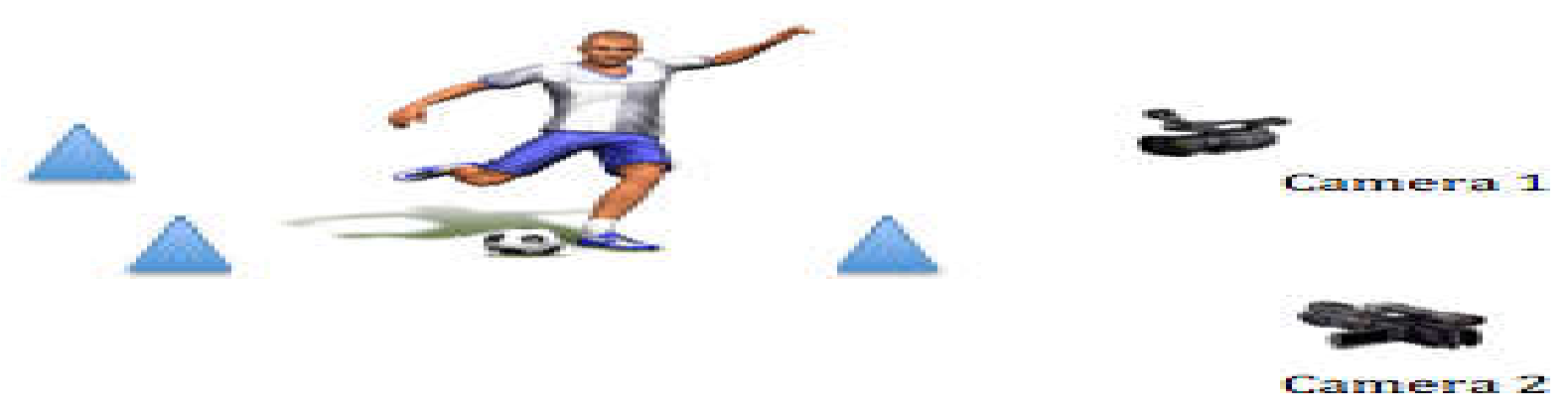

Fig.1. Study setup

\subsection{Data and Statistical Analysis}

Kicking analysis was done by uses the Sillicon Pro Coach software. This software can analyse velocity, acceleration and angle of kick of the kicking leg. Velocity, acceleration and angle at ankle need to be analysing for each frame. This data will be used for calculation to search for force while kicking. Statistical analysis was done by using Statistical Package for the Social Minitab software. The results of this analysis were use to determine the correlation between each parameter towards the force model that will be made.

\section{RESULTS AND DISCUSSION}

\subsection{Kicking Analysis}

Kicking observation was conducted by video recording and edited by making pictures according to frame, which is for every 0.02 seconds before kicking until after kicking was done. Fig. $2 \mathrm{a}$ and $2 \mathrm{~b}$ present the editing pictures according to the frame of the subject's body position and movement during kicking using dominant's leg (right and left). Kicking in each frame will be analyzed according to the angle, acceleration, kicking velocity and frame distance at ankle. For this study, the instep kick was done for 3 times. Hence, each kick has different data and need to be average. The table below illustrates how Silicon Pro Coach software analyze the kicking video and each frame with 0.02 seconds time different to obtain the data. 

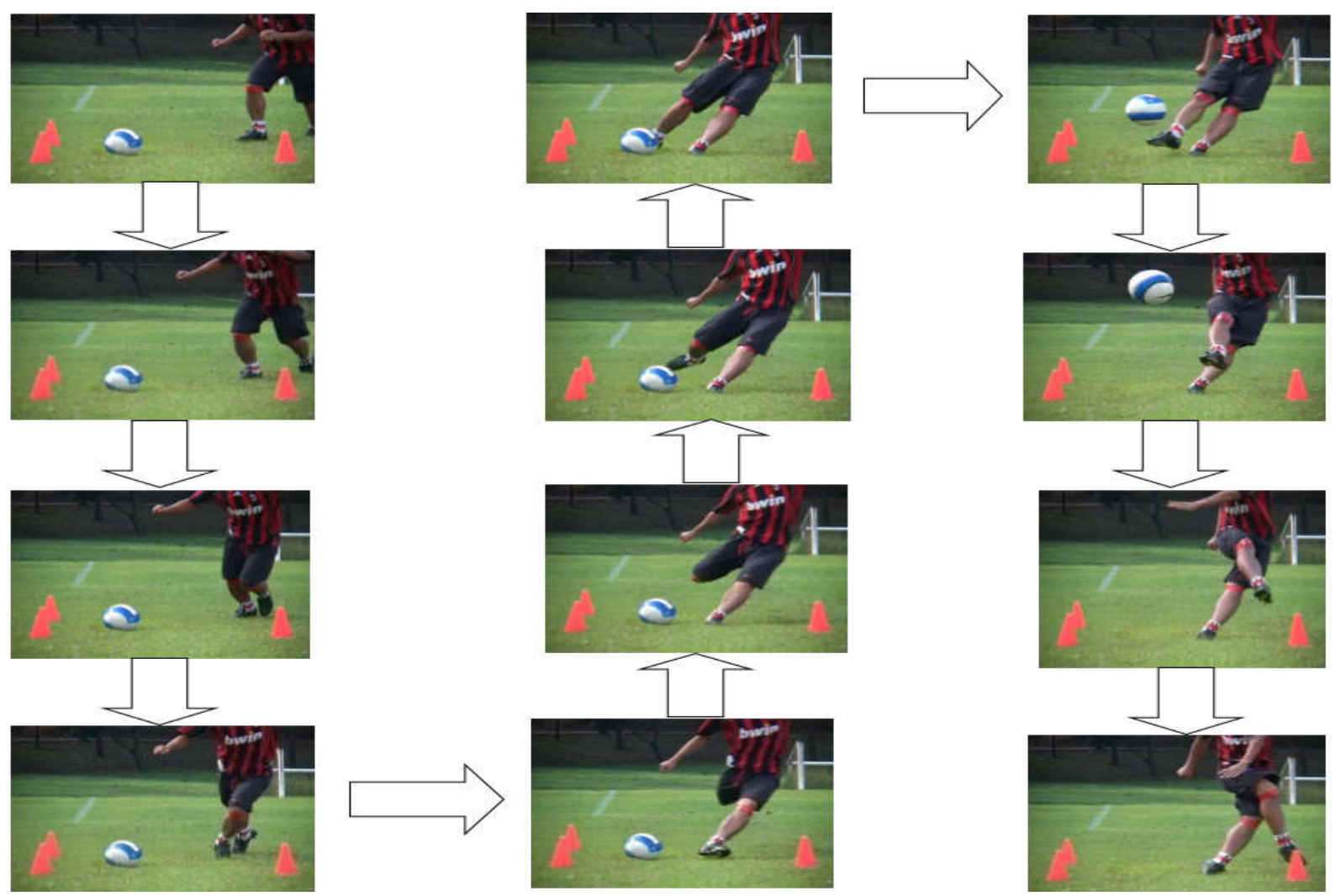

Fig.2a. Front view kicking (dominant right) according to frame
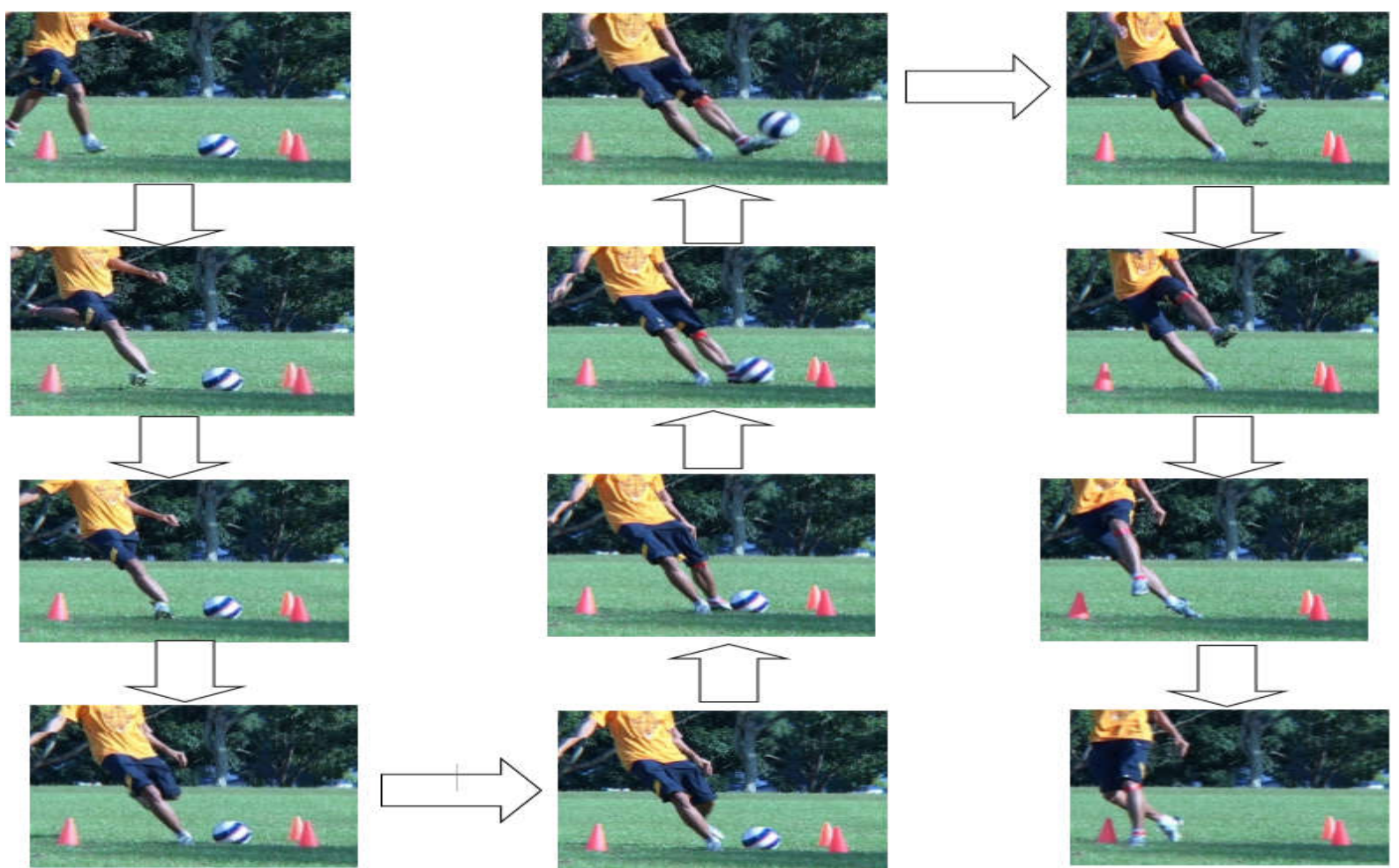

Fig.2b Front view kicking (dominant left) according to frame

Fig. $3 \mathrm{a}$ and $3 \mathrm{~b}$ show the angles when the dominant's right and left leg. Subjects starts delivering the kick and the respective angles when kicking the ball was carried out. These angles were 
measured from hip point, knee point and ankle point of the kicking leg. The result of this study indicates that the subject, which uses left leg to kick the ball at the $44^{\circ}$ angle. The findings for the angle was similar to the findings by [12] where the angle of approach is the most important aspect of this preparatory movement, which has a significant effect on soccer kick success. It found that kicking from an angled approach up to $45^{\circ}$ may increase ball speed.

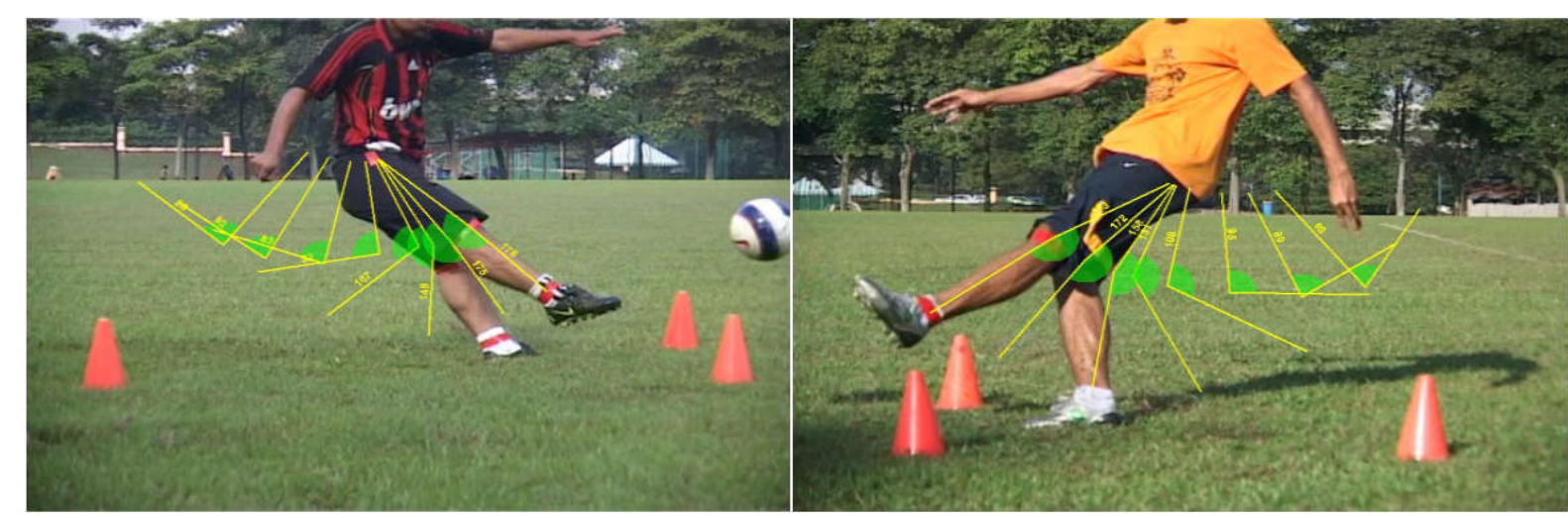

Fig.3a. The angles when the right leg subject Fig.3b. The angles when the left leg subject starts delivering the kick starts delivering the kick

Fig. $4 \mathrm{a}$ and $4 \mathrm{~b}$ show the subject started making a kicking. The analysis was made when the subject delivering a two steps run. In this figure, it shows the velocity relationship versus every time frame adopted and also the distance when making kicking. Here, the force considered is at ankle part because that part more hit the ball when making kick compared to knee part and waist. The maximum velocity for the right and left legs subjects produced in frame 4, which before the foot impact and hit into the ball. The speed at the ankle when frame 4 is $8.20 \mathrm{~m} / \mathrm{s}$ for the dominant's right leg subject and $10.52 \mathrm{~m} / \mathrm{s}$ for the dominants left leg subject. We can determine that time velocity and distance are the dependent variable while kicking. Ball speed depends on the velocity of the foot (distal segment) upon impact as well as the quality of ball-foot impact. 


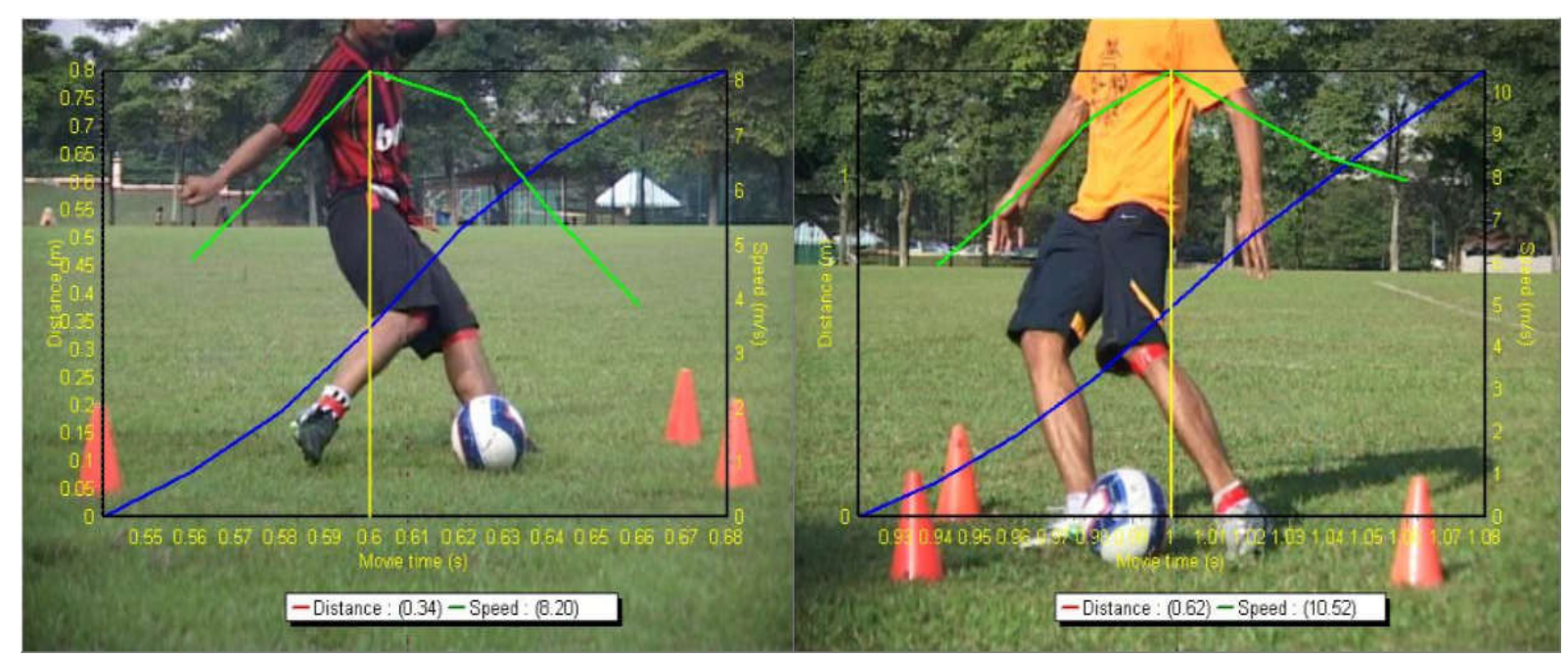

Fig.4a. The velocity relationship for the for right legs subject

Fig.4b. The velocity relationship the left legs subject

Fig. $5 \mathrm{a}$ and $5 \mathrm{~b}$ show the beginning impact in ankle and ball part which the velocity in ankle will decline consequence of the impact which occurred. The velocity for the dominant's right leg at the moment is $7.67 \mathrm{~m} / \mathrm{s}$ after the impact happened the velocity will decreased until subject finish making kicking, which velocity value lesser as much as $0.53 \mathrm{~m} / \mathrm{s}$. For the dominant's left leg show the velocity at the moment of impact was $9.50 \mathrm{~m} / \mathrm{s}$, which are $1.02 \mathrm{~m} / \mathrm{s}$ less than $10.52 \mathrm{~m} / \mathrm{s}$. The foot velocity reduction before the foot touching the ball would give the high impact to the force inflicted by foot on ball. Kicking distance will be measured after kick carried out and drop ball falling on field surface will be recorded his distance.

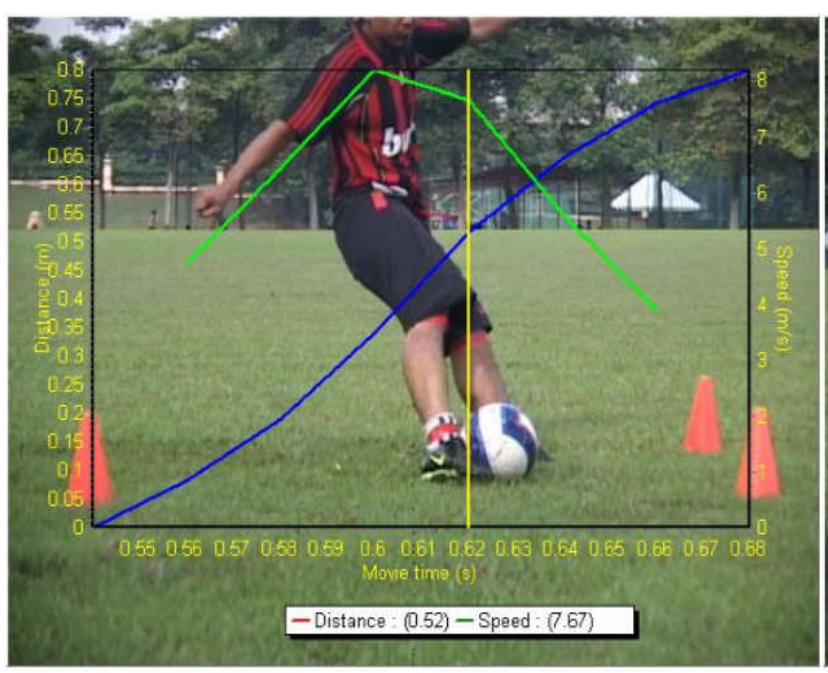

Fig.5a. Velocity against time graph at frame 5 for the right legs subject

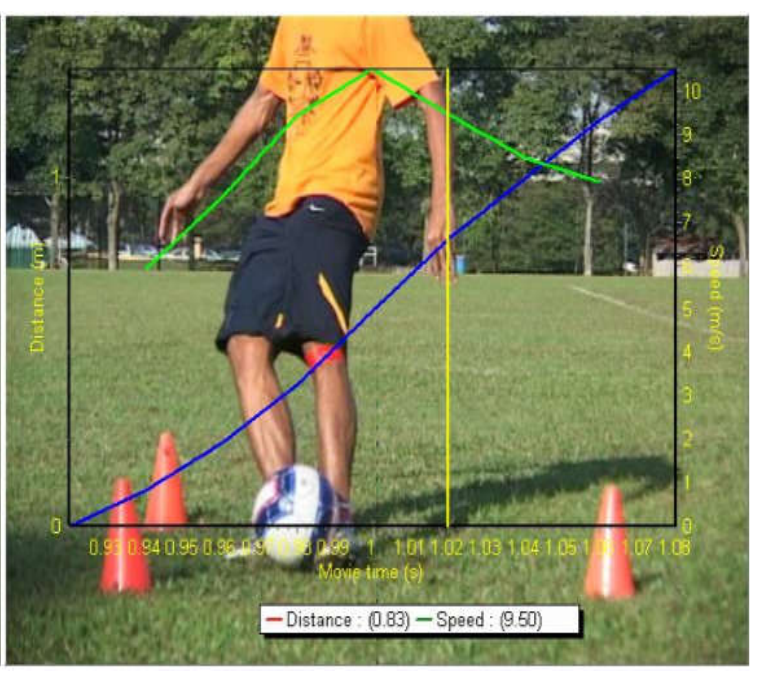

Fig.5b. Velocity against time graph at frame 5 for the left legs subject 
Table 1. The distance, velocity and force of each kick run type for dominant right and left leg

\begin{tabular}{ccccccc}
\hline & \multicolumn{3}{c}{ Dominant Right Leg } & \multicolumn{3}{c}{ Dominant Left Leg } \\
Run & Distance & Velocity & Force & Distance & Velocity & Force \\
Type & $(\mathbf{m})$ & $(\mathbf{m} / \mathbf{s})$ & $\mathbf{( N )}$ & $(\mathbf{m})$ & $(\mathbf{m} / \mathbf{s})$ & $(\mathbf{N})$ \\
\hline \multirow{2}{*}{ One step } & 40.9 & 7.74 & 5549.85 & 43.1 & 9.84 & 7130.85 \\
Two step & 45.8 & 7.88 & 5650.236 & 47.8 & 10.52 & 7623.64 \\
Three step & 47.9 & 8.82 & 5879.6 & 50.8 & 11.71 & 8486 \\
\hline
\end{tabular}

Table 1 presents the distance, velocity and force of each kick run type when subject making instep kick. From the table, the maximum velocity resultant, distance and force is found in three step run. The foot velocity before ball kicked is directly proportional with force imposed against ball. As we increased the number of run steps, the resultant force before kicking the ball also increased. From this study, the highest force recorded in frame 4 that occurs when the ankle touched the ball. The highest average force for right leg is $5879.60 \mathrm{~N}$ and the highest average velocity is $8.2 \mathrm{~m} / \mathrm{s}$. For the dominant's left leg subject, the highest average force produced in force model analysis was $8486.00 \mathrm{~N}$ and the highest average velocity was 11.71 $\mathrm{m} / \mathrm{s}$. In this case, the force considered was at the ankle part because this part hit the ball more when performing the kick compared to knee and waist part.

\subsection{Statistical Analysis-Multiple Linear Force Modelling Equations for All Variables}

The data will transfer into Statistical Package for the Social Sciences (SPSS) to analyze for each variable to the force when produce from kicking. From the multiple linear regression for all variables it recorded that $\mathrm{R}^{2}=1.000$ and the output $\mathrm{R}^{2} \times 100 \%=100 \%$ where $\mathrm{R}^{2}$ is the coefficient of determination. This can be interpreted as indicating that the model containing distance, acceleration and angle for approximately $100 \%$ of the observed variability in force. The model equation that been used is $\hat{Y}=\beta_{0}+\beta_{1} X_{1}+\beta_{2} X_{2}+\beta_{3} X_{3}$. 

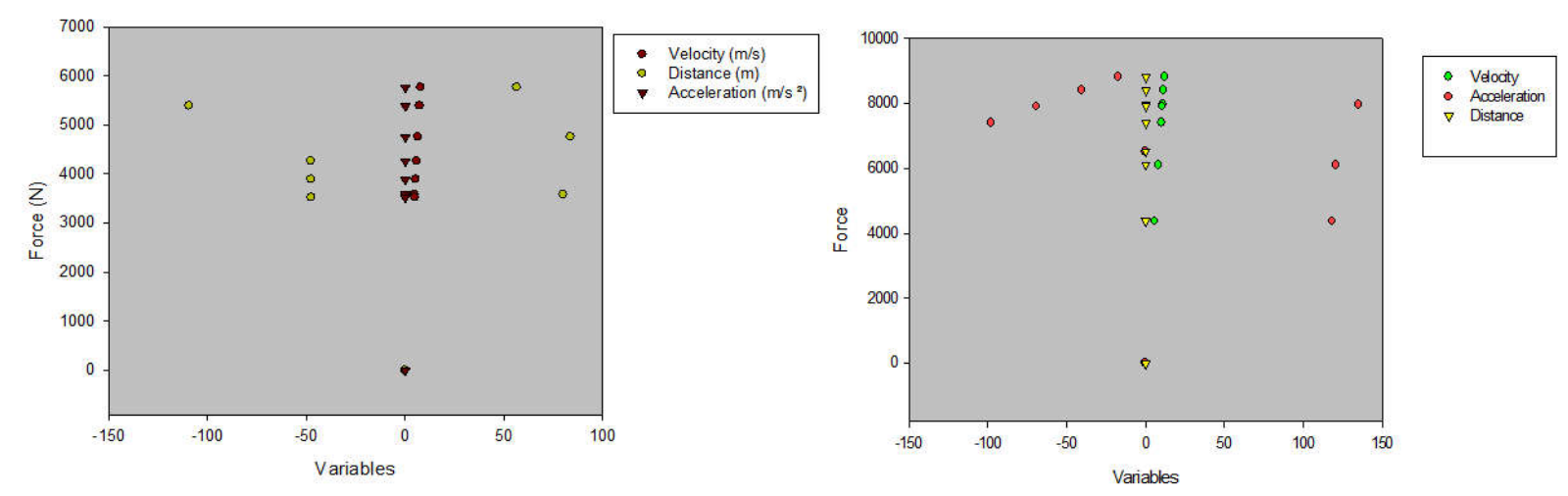

Fig.6a. Multiples modeling for all variables

Fig.6b. Multiples modeling variables for all in three step run for dominant right leg variables in three steps run for dominant left leg Fig. $6 \mathrm{a}$ and $6 \mathrm{~b}$ shows the multiple linear graphs for all the three variables considered in three step run. The Minitab output show that the least square point estimates of the model parameter for the dominant right leg are $\beta 0=-18.1, \beta 1=711, \beta 2=0.146$ and $\beta 3=396$ where $\beta 1$ is velocity, $\beta 2$ is acceleration and $\beta 3$ is distance and the least square point estimates of the model parameters are $\beta_{0}=-0.073, \beta_{1}=724, \beta_{2}=0.00114$ and $\beta_{3}=0.40$ where $\beta_{1}$ is velocity, $\beta_{2}$ is acceleration and $\beta_{3}$ is distance is for dominant left leg. Based on reference book, forecasting, time series and regression by [13] told that graph which is linearly to the regression line can accepted and assumption homoscedasticity not disturb. This mean that velocity and distance while kicking give the significant and correlation clearly for force model produced.

Table 2. The multi linear force model equation for all type run

\begin{tabular}{ccc}
\hline Run Type & Dominant Right Leg & Dominant Left Leg \\
\hline One step & $\hat{y}=-0.0047+717 \mathrm{v}+0.000062 \mathrm{a}+0.000062 \mathrm{~d}$ & $\hat{\mathrm{y}}=-2.4+721 \mathrm{v}+0.293 \mathrm{a}$ \\
Two step & $\hat{\mathrm{y}}=0.000202+717 \mathrm{v}+0.000002 \mathrm{a}-0.00035 \mathrm{~d}$ & $\hat{\mathrm{y}}=-55+738 \mathrm{v}-1.09 \mathrm{a}+461 \mathrm{~d}$ \\
Three step & $\hat{\mathrm{y}}=-18.1+711 \mathrm{v}+0.146 \mathrm{a}+396 \mathrm{~d}$ & $\hat{\mathrm{y}}=-0.073+724 \mathrm{v}+0.00114 \mathrm{a}+0.40 \mathrm{~d}$ \\
\hline
\end{tabular}

where level of ability (y), velocity (v), acceleration (a) and also distance (d).

Table 2 shows the force modelling equation for each type run. Model equation will be used is $\hat{Y}=\beta_{0}+\beta_{1} X_{1}+\beta_{2} X_{2}+\beta_{3} X_{3}$. The analysis revealed that the velocity and distance are significant on level of ability. After go through for each data that provide from Minitab software, there have the significant and no significant variable for knee. There are some suggestions to increase kicking force while perform instep kick such as when the support leg 
is close to the ball for kicking, angle of the knee of the kicking leg must be smaller than the results above to get higher. Any deformity at the knee can cause a great increase in force transmitted during activity since muscles and ligaments must exert a protective action to support the joint and these forces are added to the 'normal' forces acting on the knee.

\section{CONCLUSION}

This study had shown that the highest average forces recorded in force model analysis which was by using three step run by the subjects gave higher average force, average velocity and also the distance. The highest average force of instep kicking achieved by dominant's left leg subject is $8486.00 \mathrm{~N}$, the highest average velocity is $11.71 \mathrm{~m} / \mathrm{s}$ with longest distance kick is $50.8 \mathrm{~m}$ and the multi linear model equation is $\hat{\mathrm{y}}=-0.073+724 \mathrm{x}_{1}+0.00114 \mathrm{x}_{2}+0.40 \mathrm{x}_{3}$. This study was done to obtain the equation that relates with the variables and to develop the force model equation when the kicks were made. It will be hoped that this study would be beneficial to the Malaysian soccer player to develop better kicking techniques and prevent them from any injuries.

\section{REFERENCES}

[1] Moschini A, Smith N. Effect of shoe mass on soccer kicking velocity. In 30th Annual Conference of Biomechanics in Sports, 2012, pp. 150-153

[2] Ismail A R, Ali M F M, Deros B M, Johar M S N M, Rahman M A A. Biomechanics of instep kick using left leg for different run types. In 1st Southeast Asian Network of Ergonomics Societies Conference, 2010

[3] Asami T, Nolte V. Analysis of powerful ball kicking. Biomechanics VIII-B, 1983. 4:965-970.

[4] Hong S, Chung C, Sakamoto K, Asai T. Analysis of the swing motion on knuckling shot in soccer. Procedia Engineering, 2011, 13:176-181

[5] Kellis E L, Katis A, Gissis I. Knee biomechanics of the support leg in soccer kicks from three angles of approach. Medicine and Science in Sports and Exercise, 2004, 36(6):1017-1028

[6] Kellis E, Katis A. Biomechanical characteristics and determinants of instep soccer kick. 
Journal of Sports Science and Medicine, 2007, 6(2):154-165

[7] Lees A, Asai T, Andersen T B, Nunome H, Sterzing T. The biomechanics of kicking in soccer: A review. Journal of Sports Sciences, 2010, 28(8):805-817

[8] Luhtanen P. Kinematics and kinetics of maximal instep kicking in junior soccer players. In T. Reily, A. Lees, K. Davids, \& W. J. Murphy (Eds.), Science and football. London: E and FN Spon, 1988, pp. 441-448

[9] Ali M F, Deros B M, Ismail A R. Biomechanics analysis for dominant leg during instep kicking. Jurnal Teknologi (Sciences and Engineering), 2012, 59(Suppl. 2):37-40

[10] Price D S, Jones R, Harland A R. Soccer ball anisotropy modelling. Materials Science and Engineering: A, 2006, 420(1):100-108

[11] Sterzing T, Lange J S, Wächtler T, Müller C, Milani T L. Velocity and accuracy as performance criteria for three different soccer kicking techniques. In International Conference on Biomechanics in Sports, 2009, pp. 1-4

[12] Isokawa M, Lees A. A biomechanical analysis of the instep kick motion in soccer. Science and Football, 1988, 1:449-455

[13] Bowerman B. L., O’Connell R. T., Koehler A. B. Forecasting, time series, and regression: An applied approach. California: Thomson Brooks/Cole, 2005

\section{How to cite this article:}

Ali MFM, Yaakub N, Haris MN, Kamarudin MKA.Modeling equation of knee force during instep kicking using dominant's leg in football. J. Fundam. Appl. Sci., 2017, 9(2S), 750-760. 